\title{
Regional Conditions and Land-Use Alter the Potential Contribution of Soil Arthropods to Ecosystem Services in Grasslands
}

\author{
Klaus Birkhofer ${ }^{1 *}$, Christoph Dietrich ${ }^{2,3}$, Katharina John ${ }^{4}$, Quentin Schorpp ${ }^{5}$, \\ Andrey S. Zaitsev ${ }^{4}$ and Volkmar Wolters ${ }^{4}$
}

${ }^{1}$ Biodiversity Unit, Department of Biology, Lund University, Lund, Sweden, ${ }^{2}$ German Centre for Integrative Biodiversity Research, Leipzig, Germany, ${ }^{3}$ Institute of Biology, Leipzig University, Leipzig, Germany, ${ }^{4}$ Department of Animal Ecology, Justus Liebig University, Gießen, Germany, ${ }^{5}$ Institute of Biodiversity, Thünen Institute, Braunschweig, Germany

\section{OPEN ACCESS}

Edited by:

Alberto Orgiazzi,

European Commission, Joint

Research Centre, Italy

Reviewed by:

Aidan M. Keith,

Centre for Ecology \& Hydrology, UK Roel Van Klink,

University of Bern, Switzerland

*Correspondence: Klaus Birkhofer klaus.birkhofer@biol.lu.se

Specialty section:

This article was submitted to Agroecology and Land Use Systems,

a section of the journal

Frontiers in Ecology and Evolution

Received: 30 October 2015 Accepted: 14 December 2015

Published: 19 January 2016

Citation:

Birkhofer K, Dietrich C, John K, Schorpp Q, Zaitsev AS and Wolters V (2016) Regional Conditions and

Land-Use Alter the Potential Contribution of Soil Arthropods to Ecosystem Services in Grasslands.

Front. Ecol. Evol. 3:150. doi: 10.3389/fevo.2015.00150
We investigated the impact of regional conditions and land-use intensity on eight selected arthropod taxa of Mesostigmata (Parasitidae), Oribatida (three species), Collembola (one species), Chilopoda (two species), and Diplopoda (one species) sampled in differently managed permanent grasslands of three German study regions. By jointly analyzing changes in abundance and trophic behavior (measured as natural variation in ${ }^{15} \mathrm{~N} /{ }^{14} \mathrm{~N}$ and ${ }^{13} \mathrm{C} /{ }^{12} \mathrm{C}$ ratios) we intended to develop a framework for evaluating the impact of local and regional conditions on the ecosystem services delivered by soil animals (mainly decomposition- and predation-related services). The investigated taxa could be assorted to three major groups: (1) numerical response only, (2) numerical and trophic response and (3) trophic response only. Since the combination of taxa assembled in the individual groups does not correspond to any of the conventional soil ecological classification systems, this grouping offers a new approach for analyzing soil communities. The complementing consideration of both the direction of the numerical response and the type of the trophic response (change of the basal food source vs. trophic level shift vs. variations in isotopic niches) provided a differential insight into the effect of management and geographic differences on soil arthropods. It could be shown that the effect of land-use on the abundance of detritivorous microarthropods varies among regions, but does not induce any changes in feeding behavior. Our findings on Parasitidae indicate that carnivorous microarthropods exert substantial predation pressure on soil mesofauna and may be quite resistant to environmental changes due to high trophic flexibility. If conditions are favorable, centipedes may reach comparatively high densities in permanent grasslands and could be very important for controlling belowground pests. Concerning millipedes, isotopic signatures suggest that some species could exert a substantial disservice by feeding on roots over a wide range of land-use intensities and regional conditions. We conclude that the many consistent and significant effects found in our study support our contention that the combined analysis of numerical and trophic responses provides a promising framework for designing spatially explicit models that quantify the impact of human interventions on the delivery of ecosystem services by the soil fauna.

Keywords: soil fauna, ecosystem services, permanent grasslands, land-use intensity, stable isotopes, trophic response 


\section{INTRODUCTION}

Edaphic animals affect a wide range of ecological processes and soil-related ecosystem services (Brussaard, 1997; Heemsbergen et al., 2004; de Vries et al., 2013) with detritivores inter alia contributing to plant nutrition, carbon turnover, detoxification, and soil quality (Wardle et al., 2004; Nielsen et al., 2011). Moreover, soil predators are important natural regulators of belowground pests (Zenger and Gibb, 2001). However, spatially explicit predictions of such services and their magnitude are difficult, since the contribution of soil animals to ecosystem processes may considerably differ among sites due to local or regional differences in the abundance, the functional role or both of the species involved. The significant impact of regional conditions on the composition of edaphic animal communities is well established (Fierer et al., 2009; Birkhofer et al., 2012; Tsiafouli et al., 2015). Similarly, strong alterations of soil animal assemblages by land-use have often been reported for the local scale (e.g., Birkhofer et al., 2008). The interplay between regional conditions and local land-use is therefore likely to modify the contribution of edaphic animals to ecosystem services. It remains unknown, however, to what extent such changes manifest themselves through numerical and/or functional responses of the soil fauna to large- and small-scale differences in environmental conditions (Barrios, 2007; Crotty et al., 2014).

The study presented here focusses on edaphic arthropods of grasslands. Grassland soils host diverse invertebrate communities that are known to sensitively respond to management (e.g., Curry, 1994; Dahms et al., 2010; Menta et al., 2011). This, for example, has been demonstrated for the effects of fertilization (King and Hutchinson, 1980; Birkhofer et al., 2008), grazing (King and Hutchinson, 1976; Ponge et al., 2015), and cutting (Jensen et al., 1973; Lemanski and Scheu, 2015). As a consequence, critical shifts within soil food webs may occur (Haubert et al., 2009; Birkhofer et al., 2011; Crotty et al., 2014; Klarner et al., 2014). Unfortunately, the greening measures recently implemented by the European Commission to protect and maintain species-rich permanent grasslands do not take such human interventions into account (Common Agricultural Policy 2013: Regulation No 1307/2013 Article 4).

Most studies on the arthropods of grassland soils quantify changes in abundance patterns, while functional responses are rarely addressed. Stable isotope analysis provides a unique opportunity for overcoming this gap of knowledge (e.g., Scheu and Falca, 2000; Birkhofer et al., 2011). Concerning soil communities, this technique has been applied to determine trophic niches (Schneider et al., 2004; Chahartaghi et al., 2005), food web structure (Erdmann et al., 2007; Pollierer et al., 2009; Klarner et al., 2013), and patterns of basal resource utilization (Albers et al., 2006; Sereda et al., 2015). The ${ }^{15} \mathrm{~N} /{ }^{14} \mathrm{~N}$ ratio can be used to identify the trophic position of species in soil food webs (DeNiro and Epstein, 1981), since the heavy nitrogen isotope ${ }^{15} \mathrm{~N}$ is usually enriched in consumers compared to their food source. The ${ }^{13} \mathrm{C} /{ }^{12} \mathrm{C}$ ratio on the contrary allows for estimating the basal food resource of a consumer as it is usually only enriched by about $0.4 \%$ compared to the food source (Post, 2002). The joint analysis of these two isotope ratios therefore provides a versatile tool to measure management induced shifts in the provision of those ecosystem functions and services that depend on the trophic structure of belowground biota (Klaus et al., 2013).

Here we aim at developing a framework for evaluating the joint impact of regional conditions and land-use intensity on the abundance and functional role of edaphic animals (with function being measured as natural variation in ${ }^{15} \mathrm{~N} /{ }^{14} \mathrm{~N}$ and ${ }^{13} \mathrm{C} /{ }^{12} \mathrm{C}$ ratios). We consider such a framework as an essential prerequisite for spatially explicit predictions of decompositionand predation-related services provided by the soil fauna. The study focusses on eight selected arthropod taxa sampled in differently managed permanent grasslands of three German study regions (cf. Fischer et al., 2010). These taxa represent a wide range of soil taxonomic and functional groups.

\section{MATERIALS AND METHODS}

\section{Study Sites and Land-Use Intensity}

The grassland sites were located in three regions of Germany that span a latitudinal gradient of more than $500 \mathrm{~km}$ (DFG Biodiversity-Exploratories, Fischer et al., 2010). The northernmost region Schorfheide-Chorin (SEG) is situated in the lowlands of north-eastern Germany and soils are dominated by glacially formed, sandy bog soils. It has an approximate size of $1300 \mathrm{~m}^{2}$. The region Hainich-Dün (HEG) is located in central Germany and soils contain more clay and form stagnosols with poor water penetration. It covers an area of $\sim 1300 \mathrm{~m}^{2}$. The southernmost region Schwäbische Alb (AEG) is situated in the low mountain ranges of south-western Germany and soils are dominated by limestone derived Rendzina. The approximate size of this region is $422 \mathrm{~m}^{2}$. Grasslands included meadows, pastures, and mown pastures in each study region and all plots have not been part of a crop rotation scheme for at least 8 years. Land-use intensity was characterized by a land-use index (LUI, Blüthgen et al., 2012) that has been particularly developed for these grassland sites in the biodiversity exploratory regions. It jointly incorporates information about grazing intensity, cutting frequency, and fertilization intensity from 2008 to 2010 (i.e., average of the 3 year preceding our sampling in spring 2011).

\section{Arthropod and Plant Sampling}

All 150 grasslands of the Biodiversity-Exploratories (50 plots per region) were sampled between April 11 and April 21 in spring 2011. At each grassland site, a $2 \times 2 \mathrm{~m}$ subplot was established with a minimum distance of $20 \mathrm{~m}$ to field edges. Two soil cores with a diameter of $20 \mathrm{~cm}$, a depth of $10 \mathrm{~cm}$, and a distance of $1 \mathrm{~m}$ from each other were taken in random locations in these subplots. The vegetation was removed from the top of one soil core and the upper $5 \mathrm{~cm}$ were stored under cool conditions until soil animal extraction via a modified Kempson method commenced (Kempson et al., 1963). The second soil core was cut to a depth of $10 \mathrm{~cm}$ and immediately hand sorted for soil macrofauna (centipedes and millipedes) for $1 \mathrm{~h}$ per core. The soil fauna from both soil cores was transferred to $70 \%$ Ethanol for later identification. Though ethanol like other preservatives (e.g., formalin) can affect stable isotope values (Carabel et al., 2009), 
we do not consider this to cause a serious bias since all samples were stored and treated identically. Three randomly located samples of the growing vegetation were pooled in each subplot and processed for the plot-specific estimate of isotope ratios in basal resources. Further analyses on soil invertebrates were confined to eight arthropod taxa that occurred in all three study regions (listed in Table 1). Field work permits were issued by the responsible state environmental offices of Baden-Württemberg, Thüringen, and Brandenburg (according to $§ 72$ BbgNatSchG).

\section{Stable Isotope Analysis}

Soil arthropods and plant material were dried at $60^{\circ} \mathrm{C}$ for $24 \mathrm{~h}$ prior to stable isotope analyses and material for each sample was then homogenized with a ball mill. Depending on the body size of the respective species between 1 and 50 individuals were pooled. Between 0.25 and $0.69 \mathrm{mg}$ of soil arthropods per species and $3.0-4.0 \mathrm{mg}$ of plant material were processed for each stable isotope sample. Living plants and their debris often have fairly similar isotope ratios. This becomes obvious when comparing the results of Klaus et al. (2013) for grassland litter to those of Kleinebecker et al. (2014) for foliar material (both studies where carried out in the Biodiversity-Exploratories). Therefore, isotope values of the standing biomass were assumed to reflect isotope values of the litter available for the decomposer food web. Isotope ratios in animal and plant samples as well as reference materials were measured using a coupled system of an elemental analyzer and isotope ratio mass spectrometer (EA-IRMS). The reference used for $\delta^{13} \mathrm{C}$ and $\delta^{15} \mathrm{~N}$ analysis for vegetation samples was IA-R001 (wheat flour, $\delta^{13} \mathrm{CV}-\mathrm{PDB}=-26.43 \%$, $\delta^{15} \mathrm{NAir}=$
$2.55 \%$ ). The reference used for $\delta^{13} \mathrm{C}$ and $\delta^{15} \mathrm{~N}$ analysis of soil arthropod samples was IA-R042 (powdered bovine liver, $\left.\delta^{13} \mathrm{CV}-\mathrm{PDB}=-21.60 \%, \delta^{15} \mathrm{NAir}=7.65 \% 0\right)$ IA-R001 and IA-R042 are calibrated against and traceable to IAEA-CH-6 (sucrose, $\delta^{13} \mathrm{CV}-\mathrm{PDB}=-10.43 \%$ ) and IAEA-N-1 (ammonium sulfate, $\delta^{15}$ NAir $=0.40 \%$ ). Isotopic signatures are expressed using the $\delta$ notation with $\delta \mathrm{X}(\% \mathrm{o})=\left(\mathrm{R}_{\text {sample }}-\mathrm{R}_{\text {standard }}\right) / \mathrm{R}_{\text {standard }}$ $\times 1000$, with $\mathrm{X}$ representing the target isotope and $\mathrm{R}_{\text {sample }}$ is the ${ }^{15} \mathrm{~N} /{ }^{14} \mathrm{~N}$ or ${ }^{13} \mathrm{C} /{ }^{12} \mathrm{C}$ ratio of the sample and $\mathrm{R}_{\text {standard }}$ the respective ratio of the standard (Peterson and Fry, 1987).

Stable isotope measurements need calibration prior to comparison of signatures of soil animal species between regions. Physiological traits of plants in different regions (Chevillat et al., 2005; Kuptz et al., 2011) and regional differences in nitrogen deposition, precipitation, mean temperature (Boeckx et al., 2005), or land-use history (Kleinebecker et al., 2014) may lead to systematic differences between study regions. Studies in forest ecosystems have shown that both leaf litter and fine roots are suitable basal resources to calibrate signatures of animal species (Klarner et al., 2014). In grassland ecosystems, plant litter is not very abundant, as the limited amount of grass or herb litter is rapidly incorporated into the soil by macrodecomposers (e.g., earthworms). We therefore calibrated isotope values for soil arthropods as difference between the aboveground plant and soil arthropod samples $(\delta$ plant $-\delta$ animal) at a particular site (expressed by the notion $\Delta^{15} \mathrm{~N}$ or $\Delta^{13} \mathrm{C}$ ). The resulting enrichment values for nitrogen and carbon isotopes suggest that values are comparable to calibration by litter samples (Crotty et al., 2014; Mesostigmata N: $+6 \%$, C: $+3 \%$;

TABLE 1 | Soil arthropod taxa occurring in the grasslands of all three regions [SEG, Schorfheide-Chorin (northernmost); HEG, Hainich-Dün (central); AEG, Schwäbische Alb (southernmost)].

\begin{tabular}{|c|c|c|c|c|c|c|c|c|c|}
\hline \multirow[t]{2}{*}{ Species/Family } & \multirow[t]{2}{*}{ Taxonomic group } & \multirow[t]{2}{*}{ Trophic level } & \multirow[t]{2}{*}{$\boldsymbol{R}$} & \multicolumn{6}{|c|}{ Sites and abundances } \\
\hline & & & & SEG & $n$ & HEG & $n$ & AEG & $n$ \\
\hline \multicolumn{10}{|l|}{ MESOFAUNA } \\
\hline Parasitidae & Acari: Mesostigmata & $\mathrm{P}$ & 0.60 & 14 & $179.3 \pm 39.1$ & 14 & $117.4 \pm 19.5$ & 15 & $207.9 \pm 38.5$ \\
\hline $\begin{array}{l}\text { Eupelops occultus (Koch, } \\
\text { 1835) }\end{array}$ & Acari: Oribatida & $\mathrm{D}$ & 0.48 & 8 & $168.2 \pm 55.7$ & 3 & $54.0 \pm 15.3$ & 14 & $192.0 \pm 42.0$ \\
\hline $\begin{array}{l}\text { Tectocepheus velatus } \\
\text { (Michael, 1880) }\end{array}$ & Acari: Oribatida & $\mathrm{D}$ & 0.35 & 3 & $168.2 \pm 89.9$ & 6 & $334.9 \pm 106.2$ & 2 & $134.9 \pm 36.2$ \\
\hline $\begin{array}{l}\text { Trichoribates trimaculatus } \\
\text { (Koch, 1836) }\end{array}$ & Acari: Oribatida & $\mathrm{D}$ & 0.91 & 11 & $114.3 \pm 36.6$ & 2 & $7.9 \pm 3.9$ & 7 & $65.1 \pm 25.0$ \\
\hline $\begin{array}{l}\text { Isotoma viridis (Bourlet, } \\
\text { 1839) }\end{array}$ & Collembola: Entomobryoida & $\mathrm{D}$ & 0.69 & 4 & $122.2 \pm 52.1$ & 4 & $52.4 \pm 17.5$ & 3 & $51.7 \pm 15.8$ \\
\hline \multicolumn{10}{|l|}{ MACROFAUNA } \\
\hline $\begin{array}{l}\text { Geophilus flavus (De Geer, } \\
\text { 1778) }\end{array}$ & Chilopoda: Geophilomorpha & $P$ & 0.66 & 5 & $5.0 \pm 2.3$ & 27 & $38.7 \pm 7.6$ & 19 & $20.7 \pm 4.9$ \\
\hline $\begin{array}{l}\text { Schendyla nemorensis } \\
\text { (Koch, 1835) }\end{array}$ & Chilopoda: Geophilomorpha & $\mathrm{P}$ & 0.73 & 4 & $5.3 \pm 2.6$ & 21 & $47.7 \pm 10.5$ & 17 & $25.7 \pm 6.8$ \\
\hline $\begin{array}{l}\text { Cylindroiulus } \\
\text { caeruleocinctus (Wood, } \\
\text { 1864) }\end{array}$ & Diplopoda: Julida & $\mathrm{D}$ & 0.74 & 11 & $8.7 \pm 3.1$ & 26 & $16.7 \pm 3.2$ & 14 & $7.7 \pm 2.4$ \\
\hline
\end{tabular}

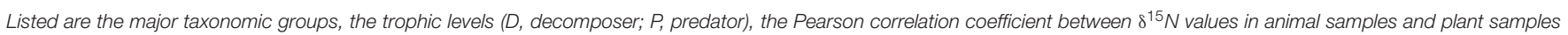

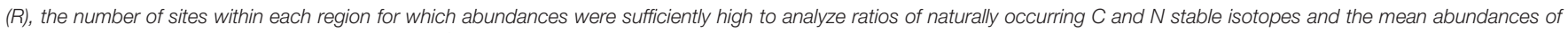
each taxonomic group per region ( $n$, individuals $\mathrm{m}^{-2}$ ) \pm standard errors of the mean for each region and taxon. 
Oribatida $\mathrm{N}:+2 \%$, C: $+2 \%$, and Entomobryid Collembola $\mathrm{N}:+2 \%$, C: $0 \% 0$ ). Our approach is further supported by strong correlations between $\delta^{15} \mathrm{~N}$ ratios in local plant samples and soil arthropod values in the respective grassland plots, with correlation coefficients ranging from 0.4 to 0.9 for the eight taxa analyzed (Table $\mathbf{1}$ ).

\section{Statistical Analysis}

Isotope values of soil arthropod species and plant samples were analyzed with permutational analysis of variance by permutation of residuals under a reduced model (PERMANOVA, Anderson, 2001) with the fixed factor "Region" (levels Schorfheide-Chorin, Hainich-Dün or Schwäbische Alb) and the continuous predictor "Land-use intensity" (LUI). All PERMANOVA analyses were based on Euclidean distances and 9999 permutations and statistical tests were performed in the software Primer-E (Clarke and Gorley, 2006) with the Permanova+ add-on (Anderson et al., 2008). Abundances of soil arthropod species were analyzed with a generalized linear model for count data (Poisson model with log link) with the same model terms as in the PERMANOVA. These analyses were performed in Statistica 12 (StatSoft Inc.).

The size of the isotopic niche in each region was calculated in the package SIAR (Parnell and Jackson, 2011) in R version 3.0.2 (R Development Core Team, 2014; http://www.r-project.org) as standardized ellipses (SEAc) that incorporate the $40 \%$ densest data points within a dataset (Jackson et al., 2011). This approach has been developed to particularly account for small and variable sample sizes (Parnell et al., 2010). Regional differences in isotopic niche size between different regions were analyzed by comparing probability distributions from Bayesian standard ellipses with 95\% credible intervals of isotopic niches. Effects of land-use intensity on isotopic niche size were analyzed by PERMANOVA (same model structure as previously described) on normalized $\Delta^{13} \mathrm{C}$ and $\Delta^{15} \mathrm{~N}$ values in a joint model.

\section{RESULTS}

\section{Abundance}

The abundance of three out of four detritivorous mesofauna species (Eupelops occultus, Tectocepheus velatus, and Isotoma viridis) was significantly related to land-use intensity, but the strength and direction of this relationship depended on the study region (Table 2). Abundances of all three species increased with land-use intensity in the southernmost region and decreased with land-use intensity in the central region (Figures 1A-C). In the northernmost region, the abundance of the collembolan species I. viridis increased with land-use intensity (Figure 1C), while that of the oribatid mite E. occultus decreased with an increase of land-use intensity (Figure 1A). Regional differences in the abundance of the two centipede species Geophilus flavus and Schendyla nemorensis (Chilopoda, Geophilomorpha) were very similar (Figures 2A,B), with the significant main effects of the factor "Region" on this parameter (Table 2) largely reflecting very low densities in the northernmost region and highest densities in the central region. The millipede species Cylindroiulus caeruleocinctus (Diplopoda, Julida) also had highest densities in the central region, but did not show very low densities in the northernmost region (Figure 2C). While no abundance effect of land-use intensity could be established for G. flavus, the abundance of $S$. nemorensis declined with land-use in all regions (Figure 3A). No significant abundance effect of region or landuse has been found for Parasitidae and the oribatid species Tricoribates trimaculatus (Table 2).

\section{Isotope Values}

Stable isotope analysis clearly separated the investigated taxa into primary consumers (oribatid mites, I. viridis, C. caeruleocinctus) with low $\Delta^{15} \mathrm{~N}$ ratios and secondary consumers (centipedes, Parasitidae) with high $\Delta^{15} \mathrm{~N}$ ratios (Figure 4). The fact that the $\Delta^{13} \mathrm{C}$ ratio of Parasitidae was in the same low range as those of detritivorous microarthropods (oribatid mites, I. viridis) indicates that this taxon selectively feeds on small soil animals located close to the basis of the decomposer food chain. The high $\Delta^{13} \mathrm{C}$ ratio of $C$. caeruleocinctus, in contrast, suggests the use of carbon from living plants. Though the intermediate $\Delta^{13} \mathrm{C}$ ratios of the two centipede species seem to indicate a somewhat unspecific feeding behavior, these values might thus also reflect the predation on soil animals with different feeding preferences (Figure 4).

The fact that no impact of land-use intensity or region on the $\Delta^{15} \mathrm{~N}$ ratios was found proves that external factors do not fundamentally change the tropic level of the eight soil taxa investigated (Table 2). Significant PERMANOVA results for the $\Delta^{13} \mathrm{C}$ ratios of two taxa indicate, however, that trophic shifts may occur. The $\Delta^{13} \mathrm{C}$ ratio of the centipede $S$. nemorensis was negatively related to land-use (Figure 3B). Significant interactions (Table 2) additionally show that the $\Delta^{13} \mathrm{C}$ ratio of this species was comparatively low in the central region and strongly declined with increasing land-use intensity in the northern- and southernmost regions (Figure 3B). Significant regional differences in the trophic behavior could be established for the oribatid mite $T$. trimaculatus (Table 2). The $\Delta^{13} \mathrm{C}$ ratio of this species was higher in the southernmost region than in the other two regions (AEG $1.9 \pm 0.6$ vs. HEG $1.3 \pm 0.3$ and SEG $1.4 \pm 0.7)$.

The overlap of isotope values for plant samples was high between the southernmost and central region, but generally lower with the northernmost region (Figure 5). The overlap in isotopic niches within species and between study regions was low for I. viridis (Figure 6C) and E. occultus (Figure 6B), but comparatively high for Parasitidae (Figure 6A), centipedes (Figures 6D,E), and millipedes (Figure 6F), respectively. Regional differences in the size of isotopic niches were confined to Parasitidae (Figure 7A: AEG vs. SEG: $P=0.031$ ) and $E$. occultus (Figure 7B: HEG vs. SEG, $P=0.042$ ). A significant effect of land-use intensity on the size of isotopic niches could only be established for the centipede $S$. nemorensis $\left[F_{(1,41)}=5.52, P=0.008\right]$.

\section{DISCUSSION}

This study aimed at developing a framework for the effect of regional conditions and land-use intensity on the soil fauna as a basis for predicting spatial variation in decomposition- and 
TABLE 2 | Results of permutational analyses of variance with the fixed factor "Region" and the continuous predictor "Land-use intensity" (mean LUI 2008-2010, Blüthgen et al., 2012) for (a) abundance, (b) resource utilization $\left(\Delta^{13} \mathrm{C}\right)$, and (c) trophic level $\left(\Delta^{15} \mathrm{~N}\right)$.

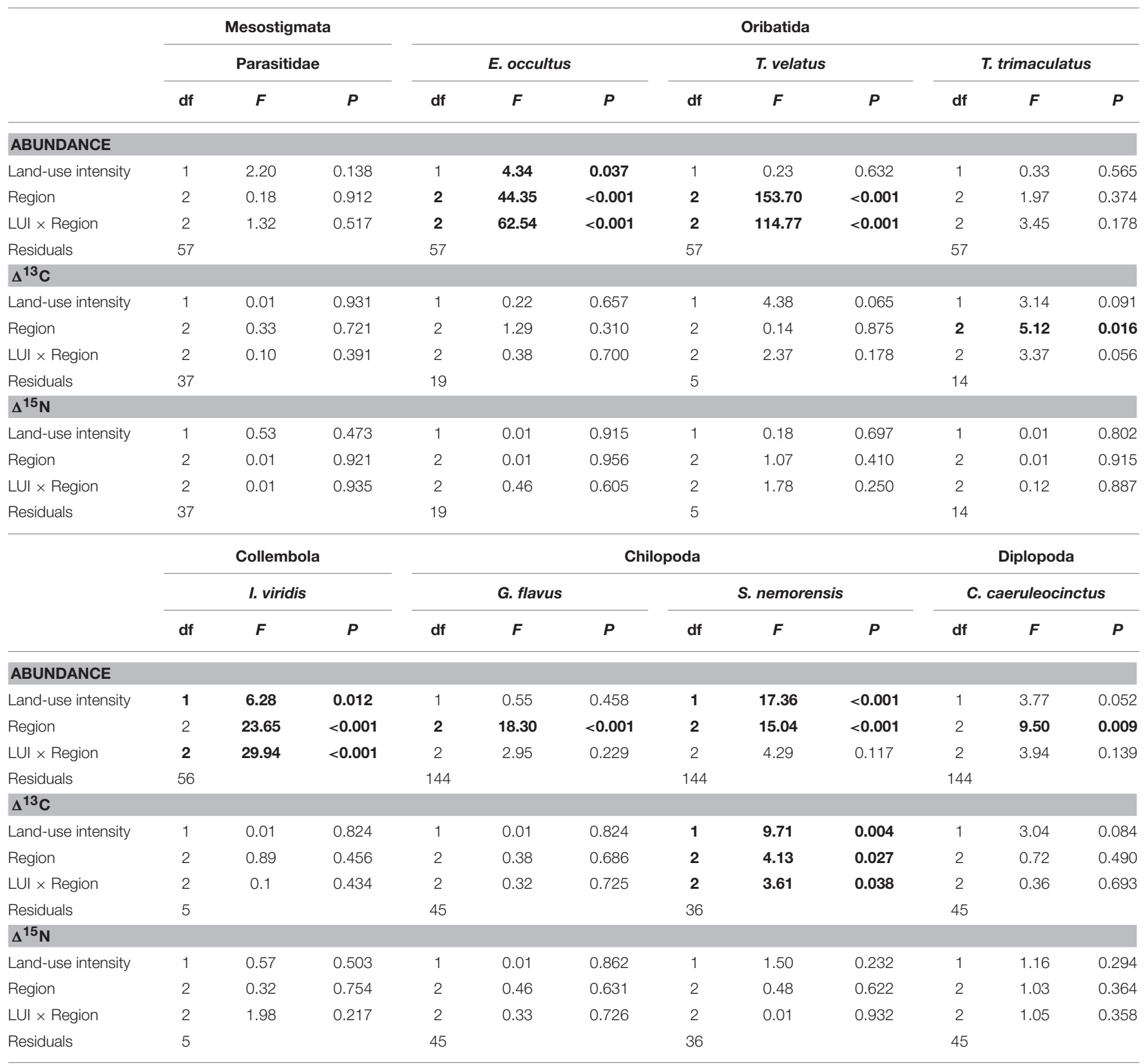

All isotope ratios are baseline-corrected for local plant resources. Significant model terms are bold.

predation-related ecosystem services (cf. Zhang et al., 2008). Against this background, our results allow us to assort the investigated taxa to three groups: (1) numerical response only ( $T$. velatus, G. flavus, C. caeruleocinctus), (2) numerical and trophic response (E. occultus, I. viridis, S. nemorensis), and (3) trophic response only (Parasitidae, T. trimaculatus). Thus, alterations in the ecosystem services provided by soil animal communities are due to complex shifts in the abundance and/or functional role of all species. Notably, our grouping does not resemble any of the established taxonomic or soil ecological classification systems (such as meso- vs. macroarthropods or detritivores vs. carnivores; Coleman et al., 2004). It thus provides an alternative framework for the evaluation of environmental effects on soil animals. Obviously, such a very coarse scheme needs to be more elaborated for becoming operational, for example by considering dominance structures of soil animal communities including abundance data for less common species. Fine-tuning is possible by additionally considering the direction of the numerical response as well as the type of the trophic response (change of the basal food source vs. trophic level shift vs. variations 


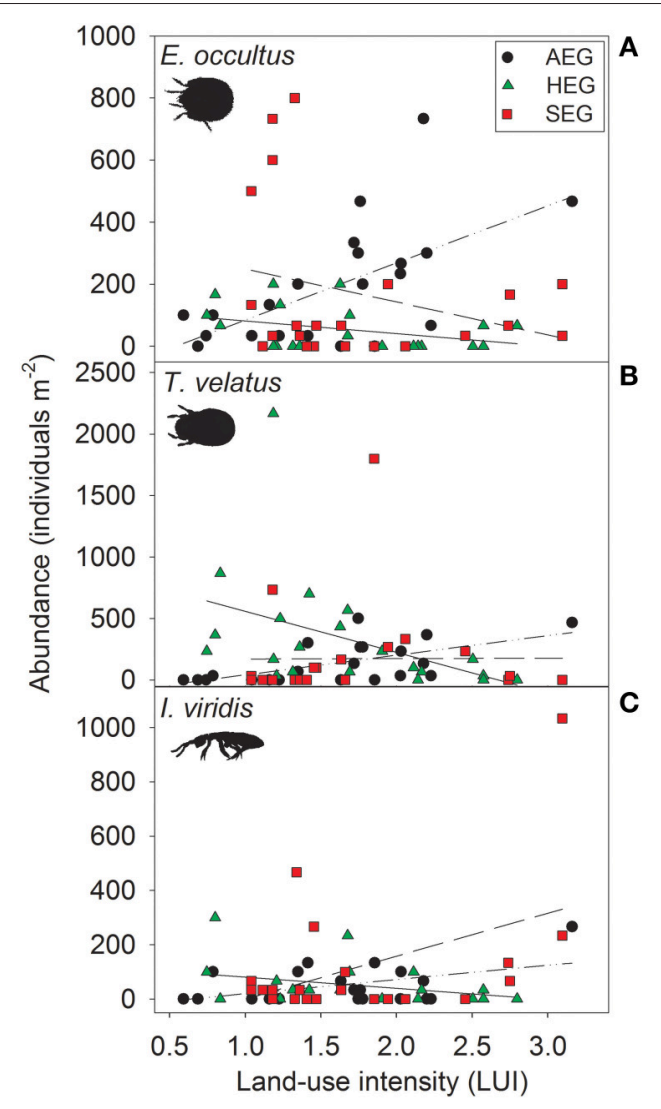

FIGURE 1 | Relationship between land-use intensity and the abundance of the three detritivorous mesofauna species Eupelops occultus (A), Tectocepheus velatus (B), and Isotoma viridis (C) in three study regions (AEG, dotted-dashed lines; HEG, solid lines; SEG, dashed lines; see Table 1 for location and abbreviation of regions).

in isotopic niches). The numerous significant effects of the factors "Region" and "Land-use intensity" on these parameters suggest that the region-specific reaction of the soil fauna to human intervention can at least partly be included in predictive approaches to ecosystem services via spatially explicit modeling (Ettema and Wardle, 2002). This, of course, would require to better understand the response of species that critically impact the provision of soil ecosystem services to regional conditions. Considering the regional differences in the isotope signatures of plants found in this study (cf. Kleinebecker et al., 2014), our approach of correcting soil animal values for this bias seems to be crucial in this context. However, the successful identification of large-scale relationships between environmental parameters and soil biota (Fierer et al., 2009; Decaens, 2010; Birkhofer et al., 2012) suggests that it is very well possible to establish region-specific response-patterns for informing predictive models. Though this is a very ambitious task, it might be an inevitable consequence of our findings that warn us against too broad generalizations of results gained from investigations carried out in single case study regions. Since our study was confined to eight common taxa, however, such far-reaching conclusions are preliminary and only intend to advance the conceptual framework mentioned above.

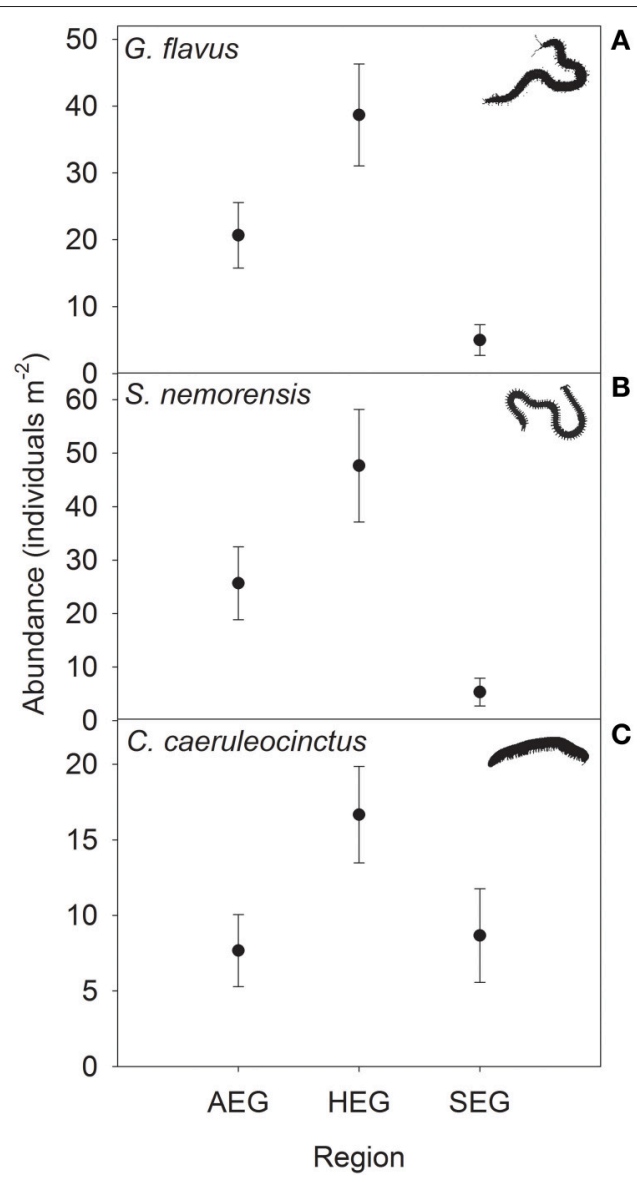

FIGURE 2 | Abundance (means \pm SE) of the centipede species (A) Geophilus flavus and (B) Schendyla nemorensis and the millipede species (C) Cylindroiulus caeruleocinctus in grassland plots in the three study regions (see Table 1 for location and abbreviation of regions).

The impact of land-use on the abundance of the microarthropods assembled in groups 1 (numerical response only) and 2 (numerical and trophic response) was significantly different among regions. This confirms that the effects of grassland management on soil mesofauna is strongly context specific (Curry, 1994). The fact, however, that the direction of the response to land-use intensity was identical for all species of these two groups in two out of three regions suggests a quite predictable impact of human intervention on detritivorous microarthropods. This conclusion is further supported by the fact that land use did not induce a trophic response of any of the microarthropod taxa investigated, i.e., major changes in the functional role do not have to be considered. Regional differences in dietary niche size and overlap nevertheless indicate a substantial influence of geographic conditions on food exploitation by most microarthropods (cf. Crotty et al., 2014). Concerning the detritivorous mesofauna, however, a significant regional shift of the basic food source could only be established for the oribatid mite T. trimaculatus (group 3, trophic response only). This species often colonizes lichens covering 


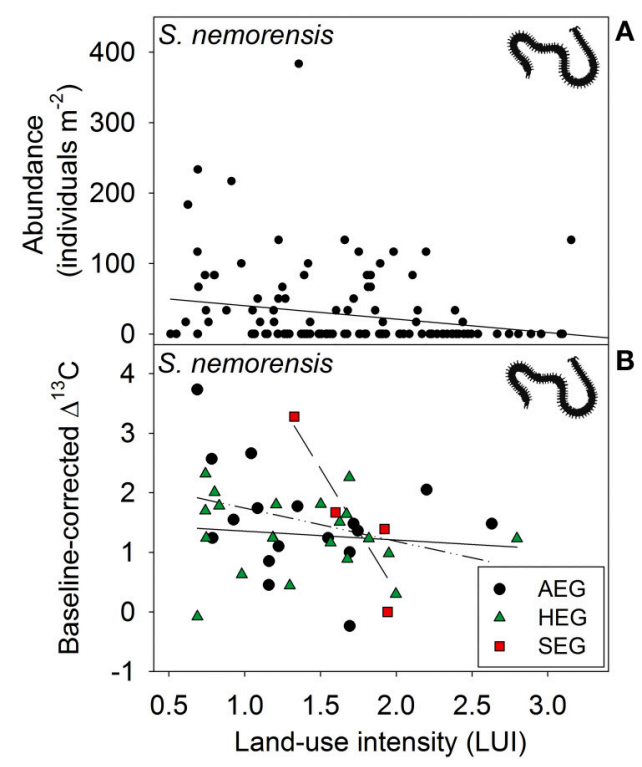

FIGURE 3 | Relationship between land-use intensity and the (A) abundance and between land-use intensity per region and the (B) $\Delta{ }^{13} \mathrm{C}$ isotope ratio (AEG, dotted and dashed line; $H E G$, solid line; and SEG, dashed line) in the centipede species Schendyla nemorensis (see Table 1 for location and abbreviation of regions).

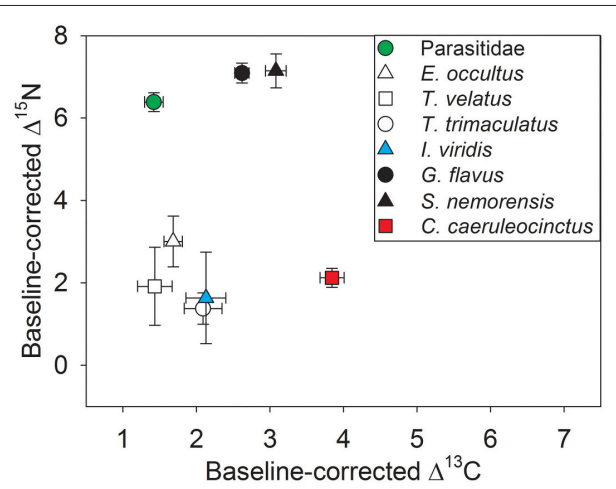

FIGURE 4 | Carbon and nitrogen stable isotope ratios (means \pm SE) for soil arthropod species with the stable isotope signature of plant samples at each site used as local baseline ( $\Delta$ values). The closer an average $\Delta$ value $\left({ }^{13} \mathrm{C}\right.$ or $\left.{ }^{15} \mathrm{~N}\right)$ is to zero on the carbon or nitrogen axis the less enriched the respective species is compared to isotopic values of plant samples from the same sampling site. For sample sizes see Table $\mathbf{1 .}$

tree trunks (Graczyk and Seniczak, 2013) and is known to be ecologically quite opportunistic. Thus, one might speculate that the abundance of this species remained quite constant, because it compensates for regional difference in resource availability by a fundamental shift in the feeding behavior, i.e., a switch from plant litter- to algae- or lichen-based diets. Such a response has already been observed for other soil detritivores (Crotty et al., 2014). Yet, the fact that the $\delta^{15} \mathrm{~N}$ signatures of all taxa included in our study exceeded those of higher plants indicates that algae

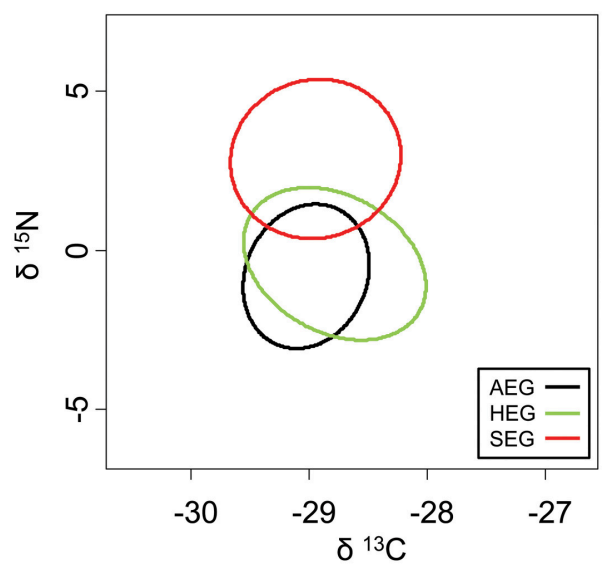

FIGURE 5 | Isotopic niches of the plant samples from the three study regions based on standardized ellipses.

or lichens are not among the major food sources of grassland arthropods (Schneider et al., 2004; Tiunov, 2007).

The millipede C. caeruleocinctus (group 1, numeric response only) was far less depleted in ${ }^{13} \mathrm{C}$ than detritivorous microarthropods. This could be explained by the utilization of root derived carbon (Klarner et al., 2013; Ferlian et al., 2015). Since this species can become a pest in sweet potato fields (Brunke et al., 2012), one might doubt the contention that millipedes have a solely beneficial role in grassland ecosystems. Though millipedes definitely contribute to litter fragmentation and structuring of soil in a wide range of ecosystems (i.e., are "ecosystem engineers" sensu Jones et al., 1997, see also Hättenschwiler et al., 2005; Hauser and Voigtländer, 2009), several species-similar to some Collembola (Endlweber et al., 2009) - may cause ecosystem disservice by consuming living plant material.

The two centipede species in our study are also listed in the numerical response groups 1 (numerical response only) and 2 (numerical and trophic response). Both species belong to the predaceous soil macrofauna, often occur in open habitats (Bonato et al., 2005) and hunt in the uppermost soil layers as well as on the soil surface (Wolters and Ekschmitt, 1997; Lewis, 2008). High densities in permanent grasslands of the southernmost and of the central study region indicate that centipedes may significantly affect ecosystem services by both preying on decomposer organisms and regulating soil-associated grassland pests (cf. Voigtländer and Düker, 2001). The intermediate $\Delta^{13} \mathrm{C}$ ratios of centipedes found in our study support the conclusion that Geophilomorpha preferentially feed on prey that consume primary carbon sources derived from roots (Tiunov, 2007) such as certain insect larvae (e.g., Diptera, Coleman et al., 2004). Since rhizophages are among the most severe pests in Central European grasslands (Alford, 2011), our results point to the potential influence of grassland centipedes on the control of belowground herbivores. Though centipedes are appreciated by some gardeners, their contribution to this essential ecosystem 
A

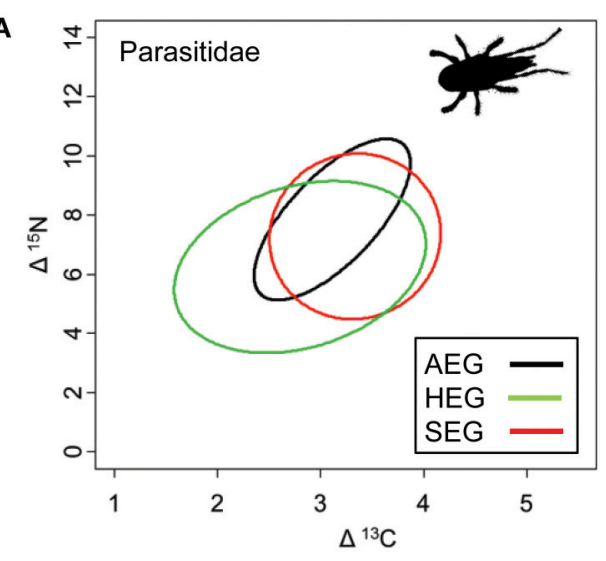

C

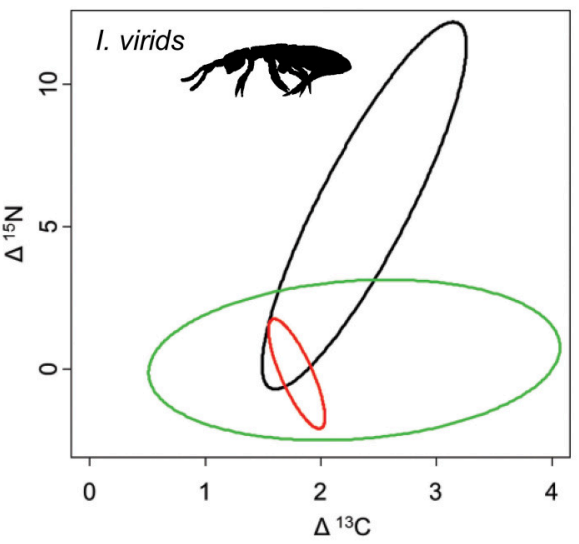

E

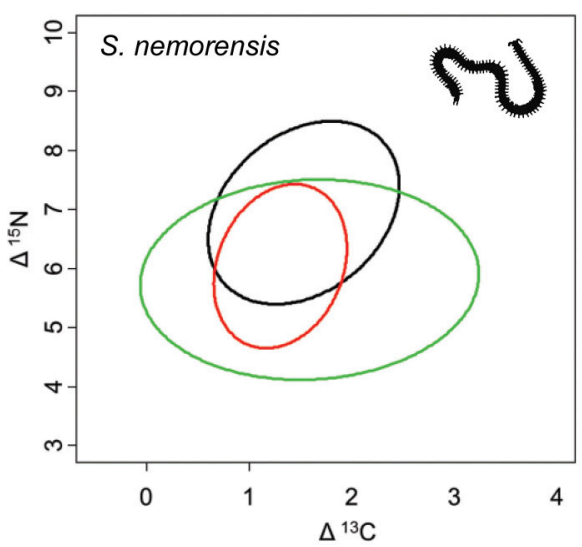

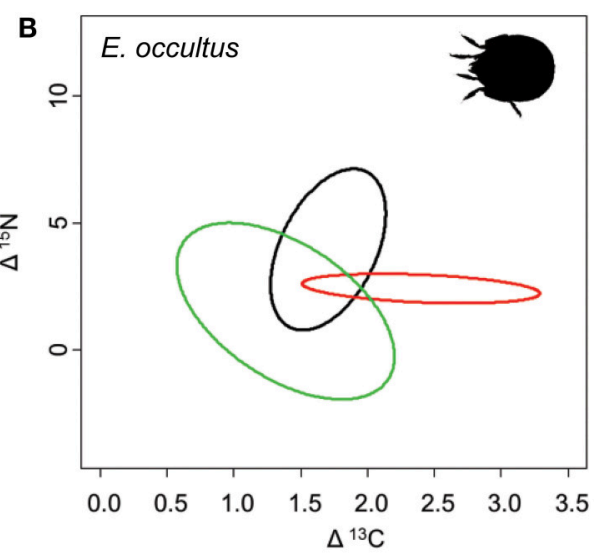
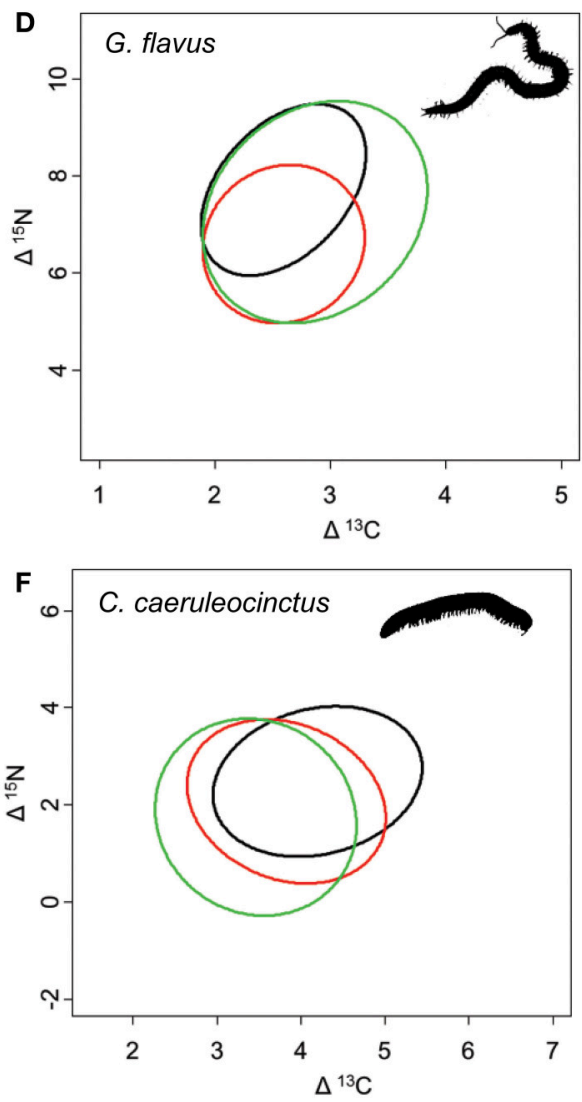

FIGURE 6 | Isotopic niches of the six soil arthropod species that were sufficiently common to calculate standardized ellipses for the feeding niches in all three study region (occurrence in a minimum of three sites per region; see Table 1 for location and abbreviation of sites). Note that standardized ellipses account for different sample sizes per region and are adjusted for small sample sizes (SEAc; Jackson et al., 2011). Taxa are (A) Parasitidae, (B) Eupelops occultus, (C) Isotoma viridis, (D) Geophilus flavus, (E) Schendyla nemorensis, and (F) Cylindroiulus caeruleocinctus.

service in permanent grasslands might have been underestimated in the past (see also Poser, 1990).

Low abundance of centipedes in the northernmost region most probably results from the adverse effects of both unfavorable soil conditions (Barlow, 1957; Wolters and Ekschmitt, 1997) and reduced availability of important food sources (in particular earthworms; Birkhofer et al., 2012). Though our findings indicate a very consistent effect of regional conditions on centipede abundance, the trophic response of the two species to land-use intensity was very different. G. flavus which is fairly well adapted to anthropogenic habitats (Bonato et al., 2005) does not seem to respond to this factor at all. In contrast, the eurytopic species S. nemorensis (Berg and Hemerik, 2004) declined in abundance with land-use intensity and also showed a significant trophic response to land-use intensity. Decreasing $\Delta^{13} \mathrm{C}$ values of $S$. nemorensis with increasing land-use 


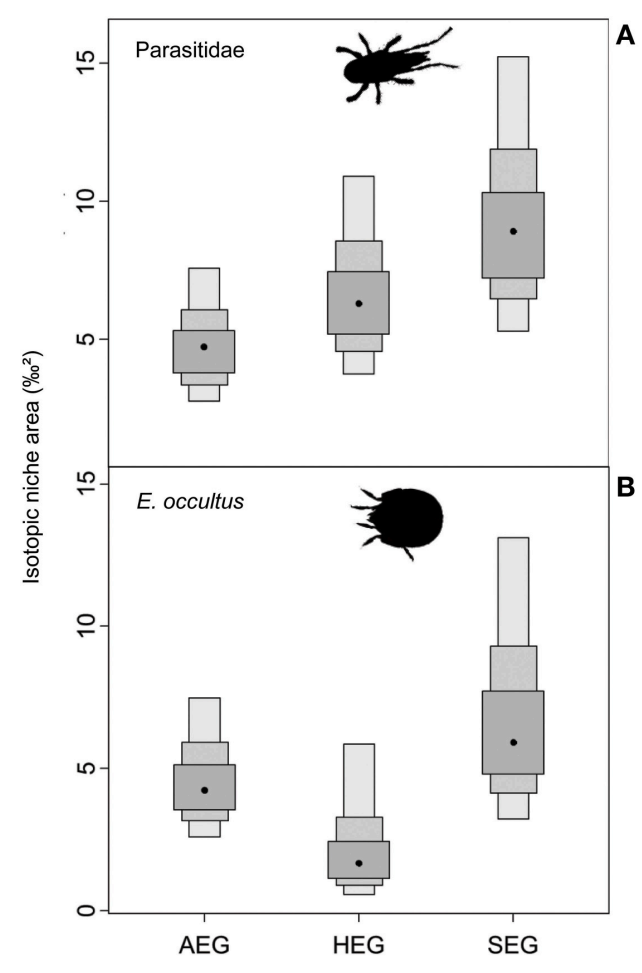

FIGURE 7 | Probability distributions for the size of isotopic niches in different regions from Bayesian standard ellipses with 95, 75, and $50 \%$ credible intervals (light to dark gray). Shown are soil arthropod species with differences between at least two regions $(P<0.05)$. Taxa are (A) Parasitidae and (B) Eupelops occultus (see Table $\mathbf{1}$ for location and abbreviation of regions).

intensity suggest a shift of prey from rhizophages to saprophages (Pollierer et al., 2009). Considering the different response patterns of the micro- and macrosaprophages investigated in our study to land use, this could be explained by an increased consumption of taxa that were not adversely affected by high management intensity. Centipedes of grassland habitats are known to switch between prey groups even within individual years (Juen and Traugott, 2007). Management may thus alter ecosystem services (biological control of root-herbviores) and disservices (reduction of decomposition processes) provided by sensitive centipede species. Trophic effects of land-use might be even more severe than indicated by our isotope analyses, since the decline of $\Delta^{13} \mathrm{C}$ values could have been partly masked by the fact that Geophilomorpha consume considerable amounts of earthworms (Lewis, 2008), which often have high $\delta^{13} \mathrm{C}$ ratios (Pollierer et al., 2009).

Comparatively low $\Delta^{13} \mathrm{C}$ values of Parasitidae (group 3: trophic response only) confirm that these predaceous microarthropods primarily consume species that feed on decomposing litter (Klarner et al., 2013). However, our finding that this taxon adjusts its trophic niche to regional conditions also suggests a rather flexible feeding behavior of this taxon (Curry, 1994). Trophic flexibility most probably contributed to the ability for maintaining similar abundance levels under all of the environmental conditions covered in our study. Due to the coarse taxonomic resolution, the flexible response of Parasitidae can be explained either by a change in species composition or by a trophic response of individual species. However, in contrast to the classification suggested by Klarner et al. (2013) for forest ecosystems the trophic niche of Parasitidae inhabiting grassland soils significantly differed from that of the centipedes discussed above. This highlights the fact that very strong changes in ecosystem structure (such as the conversion of deciduous forests to permanent grasslands) may substantially alter the functional role of several taxa in belowground communities. Thus, findings on the feeding behavior and trophic position of edaphic animals pooled to coarse taxonomic groups cannot simply be extrapolated from one ecosystem to the other.

To conclude, the combined investigation of numerical and trophic response patterns gave us a differential insight into the impact of land-use and regional conditions on edaphic arthropods. Though stable isotope analyses have become quite popular in soil ecology over the last decades, this approach has rarely been used to complement the numerous comparative studies on the abundance of the belowground fauna. Considering that this new classification system is derived from the several consistent and significant effects of management and geographic context on the abundance and feeding behavior of soil arthropods, this seems to be a serious shortcoming. We are confident that this integrative approach provides a promising framework for designing spatially explicit models that quantify the impact of human interventions on the delivery of ecosystem services by the soil fauna.

\section{AUTHOR CONTRIBUTIONS}

$\mathrm{KB}$ designed the study, participated in the sampling, supervised identification, analyzed the data, developed the paper, and wrote the manuscript. CD, KJ, and QS participated in the sampling, identified sample material, analyzed the data, and contributed to the manuscript writing. AZ supervised identification and wrote the manuscript. VW designed the study, developed the paper and wrote the manuscript.

\section{ACKNOWLEDGMENTS}

We appreciate comments of two referees to an earlier version of this manuscript. We thank the managers of the three Exploratories, Kirsten Reichel-Jung, Swen Renner, Katrin Hartwich, Sonja Gockel, Kerstin Wiesner, and Martin Gorke for their work in maintaining the plot and project infrastructure; Christiane Fischer and Simone Pfeiffer for giving support through the central office, Michael Owonibi for managing the central data base, and Markus Fischer, Eduard Linsenmair, Dominik Hessenmöller, Jens Nieschulze, Daniel Prati, Ingo Schöning, François Buscot, Ernst-Detlef Schulze, Wolfgang W. Weisser, and the late Elisabeth Kalko for their role in setting up the Biodiversity Exploratories project. The work has been (partly) funded by the DFG Priority Program 1374 "InfrastructureBiodiversity-Exploratories" (Refno. WO670/7-2). Field work permits were issued by the responsible state environmental offices of Baden-Württemberg, Thüringen, and Brandenburg (according to $\S 72 \mathrm{BbgNatSchG).}$ 


\section{REFERENCES}

Albers, D., Schaefer, M., and Scheu, S. (2006). Incorporation of plant carbon into the soil animal food web of an arable system. Ecology 87, 235-245. doi: 10.1890/04-1728

Alford, D. V. (2011). Plant Pests. London: HarperCollins.

Anderson, M., Gorley, R. N., and Clarke, R. K. (2008). Permanova+ for Primer: Guide to Software and Statistical Methods. Plymouth: Primer-E.

Anderson, M. J. (2001). A new method for non-parametric multivariate analysis of variance. Austral Ecol. 26, 32-46. doi: 10.1111/j.1442-9993.2001. 01070.pp.x

Barlow, C. A. (1957). A Factorial Analysis of Distribution in Three Species of Diplopods. Doctoral dissertation, Ponsen \& Locijen.

Barrios, E. (2007). Soil biota, ecosystem services and land productivity. Ecol. Econom. 64, 269-285. doi: 10.1016/j.ecolecon.2007.03.004

Berg, M. P., and Hemerik, L. (2004). Secondary succession of terrestrial isopod, centipede, and millipede communities in grasslands under restoration. Biol. Fert. Soils 40, 163-170. doi: 10.1007/s00374-004-0765-z

Birkhofer, K., Bezemer, T. M., Bloem, J., Bonkowski, M., Christensen, S., Dubois, D., et al. (2008). Long-term organic farming fosters below and aboveground biota: implications for soil quality, biological control and productivity. Soil Biol. Biochem. 40, 2297-2308. doi: 10.1016/j.soilbio.2008.05.007

Birkhofer, K., Fließbach, A., Wise, D. H., and Scheu, S. (2011). Arthropod food webs in organic and conventional wheat farming systems of an agricultural long-term experiment: a stable isotope approach. Agr. Forest Entomol. 13, 197-204. doi: 10.1111/j.1461-9563.2010.00511.x

Birkhofer, K., Schöning, I., Alt, F., Herold, N., Klarner, B., Maraun, M., et al. (2012). General relationships between abiotic soil properties and soil biota across spatial scales and different land-use types. PLOS ONE 7:e43292. doi: 10.1371/journal.pone.0043292

Blüthgen, N., Dormann, C. F., Prati, D., Klaus, V. H., Kleinebecker, T., Hölzel, N., et al. (2012). A quantitative index of land-use intensity in grasslands: integrating mowing, grazing and fertilization. Basic Appl. Ecol. 13, 207-220. doi: 10.1016/j.baae.2012.04.001

Boeckx, P., Paulino, L., Oyarzún, C., Cleemput, O. V., and Godoy, R. (2005). Soil $\delta 15 \mathrm{~N}$ patterns in old-growth forests of southern Chile as integrator for N-cycling. Isotopes Environ. Health Stud. 41, 249-259. doi: $10.1080 / 10256010500230171$

Bonato, L., Minelli, A., and Spungis, V. (2005). Geophilomorph Centipedes of Latvia (Chilopoda, Geophilomorpha). Lat. Entomol. 42, 5-17.

Brunke, A. J., O’Keefe, L., Bahlai, C. A., Sears, M. K., and Hallett, R. H. (2012). Guilty by association: an evaluation of millipedes as pests of carrot and sweet potato. J. Appl. Entomol. 136, 772-780. doi: 10.1111/j.1439-0418.2012.01708.x

Brussaard, L. (1997). Biodiversity and ecosystem functioning in soil. Ambio 26, 563-570.

Carabel, S., Verísimo, P., and Freire, J. (2009). Effects of preservatives on stable isotope analyses of four marine species. Estuarine Coast. Shelf Sci. 82, 348-350. doi: 10.1016/j.ecss.2009.01.011

Chahartaghi, M., Langel, R., Scheu, S., and Ruess, L. (2005). Feeding guilds in Collembola based on nitrogen stable isotope ratios. Soil Biol. Biochem. 37, 1718-1725. doi: 10.1016/j.soilbio.2005.02.006

Chevillat, V. S., Siegwolf, R. T., Pepin, S., and Körner, C. (2005). Tissue-specific variation of $\delta^{13} \mathrm{C}$ in mature canopy trees in a temperate forest in central Europe. Basic Appl. Ecol. 6, 519-534. doi: 10.1016/j.baae.2005.04.008

Clarke, K. R., and Gorley, R. N. (2006). PRIMER Version 6: User Manual/Tutorial. Plymouth: PRIMER-E.

Coleman, D. C., Crossley, D. A., and Hendrix, P. F. (2004). Fundamentals of Soil Ecology. New York, NY: Academic press.

Crotty, F. V., Blackshaw, R. P., Adl, S. M., Inger, R., and Murray, P. J. (2014). Divergence of feeding channels within the soil food web determined by ecosystem type. Ecol. Evol. 4, 1-13. doi: 10.1002/ece3.905

Curry, J. P. (1994). Grassland Invertebrates. London: Chapman \& Hall.

Dahms, H., Mayr, S., Birkhofer, K., Chauvat, M., Melnichnova, E., Wolters, V., et al. (2010). Contrasting diversity patterns of epigeic arthropods between grasslands of high and low agronomic potential. Basic Appl. Ecol. 11, 6-14. doi: 10.1016/j.baae.2009.06.004

Decaens, T. (2010). Macroecological patterns in soil communities. Global Ecol. Biogeogr. 19, 287-302. doi: 10.1111/j.1466-8238.2009.00517.x
DeNiro, M. J., and Epstein, S. (1981). Influence of diet on the distribution of nitrogen isotopes in animals. Geochim. Cosmochim. Acta 45, 341-351. doi: 10.1016/0016-7037(81)90244-1

de Vries, F. T., Thébault, E., Liiri, M., Birkhofer, K., Tsiafouli, M. A., Bjørnlund, L., et al. (2013). Soil food web properties explain ecosystem services across European land use systems. Proc. Nat. Acad. Sci. U.S.A. 110, 14296-14301. doi: $10.1073 /$ pnas. 1305198110

Endlweber, K., Ruess, L., and Scheu, S. (2009). Collembola switch diet in presence of plant roots thereby functioning as herbivores. Soil Biol. Biochem. 41, 1151-1154. doi: 10.1016/j.soilbio.2009.02.022

Erdmann, G., Otte, V., Langel, R., Scheu, S., and Maraun, M. (2007). The trophic structure of bark-living oribatid mite communities analysed with stable isotopes $\left({ }^{15} \mathrm{~N},{ }^{13} \mathrm{C}\right)$ indicates strong niche differentiation. Exp. Appl. Acarol. 41, 1-10. doi: 10.1007/s10493-007-9060-7

Ettema, C. H., and Wardle, D. A. (2002). Spatial soil ecology. Trends Ecol. Evol. 17, 177-183. doi: 10.1016/S0169-5347(02)02496-5

Ferlian, O., Klarner, B., Langeneckert, A. E., and Scheu, S. (2015). Trophic niche differentiation and utilisation of food resources in collembolans based on complementary analyses of fatty acids and stable isotopes. Soil Biol. Biochem. 82, 28-35. doi: 10.1016/j.soilbio.2014.12.012

Fierer, N., Strickland, M. S., Liptzin, D., Bradford, M. A., and Cleveland, C. C. (2009). Global patterns in belowground communities. Ecol. Lett. 12, 1238-1249. doi: 10.1111/j.1461-0248.2009.01360.x

Fischer, M., Bossdorf, O., Gockel, S., Hänsel, F., Hemp, A., Hessenmöller, D., et al. (2010). Implementing large-scale and long-term functional biodiversity research: the biodiversity exploratories. Basic Appl. Ecol. 11, 473-485. doi: 10.1016/j.baae.2010.07.009

Graczyk, R., and Seniczak, S. (2013). Oribatid mites (Acari: Oribatida) from roofs of houses in Sogn og Fjordane (Norway). Biol. Lett. 50, 77-85. doi: 10.2478/biolet-2013-0012

Hättenschwiler, S., Tiunov, A. V., and Scheu, S. (2005). Biodiversity and litter decomposition in terrestrial ecosystems. Ann. Rev. Ecol. Evol. Sys. 36, 191-218. doi: 10.1146/annurev.ecolsys.36.112904.151932

Haubert, D., Birkhofer, K., Fließbach, A., Gehre, M., Scheu, S., and Ruess, L. (2009). Trophic structure and major trophic links in conventional versus organic farming systems as indicated by carbon stable isotope ratios of fatty acids. Oikos 118, 1579-1589. doi: 10.1111/j.1600-0706.2009.17587.x

Hauser, H., and Voigtländer, K. (2009). Doppelfüßer (Diplopoda) Ostdeutschlands: Bestimmung, Biologie und Verbreitung. Göttingen: DJN.

Heemsbergen, D. A., Berg, M. P., Loreau, M., van Hal, J. R., Faber, J. H., and Verhoef, H. A. (2004). Biodiversity effects on soil processes explained by interspecific functional dissimilarity. Science 306, 1019-1020. doi: 10.1126/science. 1101865

Jackson, A. L., Inger, R., Parnell, A. C., and Bearhop, S. (2011). Comparing isotopic niche widths among and within communities: SIBER-Stable Isotope Bayesian Ellipses in R. J. Anim. Ecol. 80, 595-602. doi: 10.1111/j.1365-2656.2011.01806.x

Jensen, P., Jacobson, G. L., and Willard, D. E. (1973). Effects of mowing and raking on Collembola. Ecology 54, 564-572. doi: 10.2307/1935341

Jones, C. G., Lawton, J. H., and Shachak, M. (1997). Positive and negative effects of organisms as physical ecosystem engineers. Ecology 78, 1946-1957. doi: 10.1890/0012-9658(1997)078[1946:PANEOO]2.0.CO;2

Juen, A., and Traugott, M. (2007). Revealing species-specific trophic links in soil food webs: molecular identification of scarab predators. Mol. Ecol. 16, 1545-1557. doi: 10.1111/j.1365-294X.2007.03238.x

Kempson, D., Lloyd, M., and Ghelardi, R. (1963). A new extractor for woodland litter. Pedobiologia 3, 1-21.

King, K. L., and Hutchinson, K. J. (1976). The effects of sheep stocking intensity on the abundance and distribution of mesofauna in pastures. J. Appl. Ecol. 13, 41-55. doi: 10.2307/2401928

King, K. L., and Hutchinson, K. J. (1980). Effects of superphosphate and stocking intensity on grassland microarthropods. J. Appl. Ecol. 17, 581-591. doi: $10.2307 / 2402638$

Klarner, B., Ehnes, R. B., Erdmann, G., Eitzinger, B., Pollierer, M. M., Maraun, M., et al. (2014). Trophic shift of soil animal species with forest type as indicated by stable isotope analysis. Oikos 123, 1173-1181. doi: 10.1111/j.16000706.2013.00939.x

Klarner, B., Maraun, M., and Scheu, S. (2013). Trophic diversity and niche partitioning in a species rich predator guild-Natural variations in stable isotope 
ratios $\left({ }^{13} \mathrm{C} /{ }^{12} \mathrm{C},{ }^{15} \mathrm{~N} /{ }^{14} \mathrm{~N}\right)$ of mesostigmatid mites (Acari, Mesostigmata) from Central European beech forests. Soil Biol. Biochem. 57, 327-333. doi: 10.1016/j.soilbio.2012.08.013

Klaus, V. H., Hölzel, N., Prati, D., Schmitt, B., Schöning, I., Schrumpf, M., et al. (2013). Organic vs. conventional grassland management: Do ${ }^{15} \mathrm{~N}$ and ${ }^{13} \mathrm{C}$ isotopic signatures of hay and soil samples differ? PLOS ONE 8:e78134. doi: 10.1371/journal.pone.0078134

Kleinebecker, T., Hölzel, N., Prati, D., Schmitt, B., Fischer, M., and Klaus, V. H. (2014). Evidence from the real world: ${ }^{15} \mathrm{~N}$ natural abundances reveal enhanced nitrogen use at high plant diversity in Central European grasslands. J. Ecol. 102, 456-465. doi: 10.1111/1365-2745.12202

Kuptz, D., Fleischmann, F., Matyssek, R., and Grams, T. E. (2011). Seasonal patterns of carbon allocation to respiratory pools in $60-\mathrm{yr}-$ old deciduous (Fagus sylvatica) and evergreen (Picea abies) trees assessed via whole-tree stable carbon isotope labeling. New Phytol. 191, 160-172. doi: 10.1111/j.14698137.2011.03676.x

Lemanski, K., and Scheu, S. (2015). The influence of fertilizer addition, cutting frequency and herbicide application on soil organisms in grassland. Biol. Fert. Soils 51, 197-205. doi: 10.1007/s00374-014-0963-2

Lewis, J. G. E. (2008). The Biology of Centipedes. Cambridge: Cambridge University Press.

Menta, C., Leoni, A., Gardi, C., and Conti, F. D. (2011). Are grasslands important habitats for soil microarthropod conservation? Biodiv. Conser. 20, 1073-1087. doi: 10.1007/s10531-011-0017-0

Nielsen, U. N., Ayres, E., Wall, D. H., and Bardgett, R. D. (2011). Soil biodiversity and carbon cycling: a review and synthesis of studies examining diversityfunction relationships. Eur. J. Soil Sci. 62, 105-116. doi: 10.1111/j.13652389.2010.01314.x

Parnell, A. C., Inger, R., Bearhop, S., and Jackson, A. L. (2010). Source partitioning using stable isotopes: coping with too much variation. PloS ONE 5:e9672. doi: 10.1371/journal.pone.0009672

Parnell, A. C., and Jackson, A. (2011). SIAR: Stable Isotope Analysis in R. R Package Version 4.1.3.

Peterson, B. J., and Fry, B. (1987). Stable isotopes in ecosystem studies. Ann. Rev. Ecol. Sys. 18, 293-320. doi: 10.1146/annurev.es.18.110187.001453

Pollierer, M. M., Langel, R., Scheu, S., and Maraun, M. (2009). Compartmentalization of the soil animal food web as indicated by dual analysis of stable isotope ratios $\left({ }^{15} \mathrm{~N} /{ }^{14} \mathrm{~N}\right.$ and $\left.{ }^{13} \mathrm{C} /{ }^{12} \mathrm{C}\right)$. Soil Biol. Biochem. 41, 1221-1226. doi: 10.1016/j.soilbio.2009.03.002

Ponge, J. F., Salmon, S., Benoist, A., and Geoffroy, J. J. (2015). Soil macrofaunal communities are heterogeneous in heathlands with different grazing intensity. Pedosphere 25, 524-533. doi: 10.1016/S1002-0160(15)30033-3

Poser, T. (1990). "The influence of litter manipulation on the centipedes of a beech wood," in Proceedings of the 7th International Congress on Myriapods, ed A. Minelli (Leiden: Brill), 235-245.

Post, D. M. (2002). The long and short of food-chain length. Trends Ecol. Evol. 17, 269-277. doi: 10.1016/S0169-5347(02)02455-2
R Development Core Team (2014). R: A Language and Environment for Statistical Computing. Vienna: R Foundation for Statistical Computing.

Scheu, S., and Falca, M. (2000). The soil food web of two beech forests (Fagus sylvatica) of contrasting humus type: stable isotope analysis of a macro-and a mesofauna-dominated community. Oecologia 123, 285-296. doi: 10.1007/s004420051015

Schneider, K., Migge, S., Norton, R. A., Scheu, S., Langel, R., Reineking, A., et al. (2004). Trophic niche differentiation in soil microarthropods (Oribatida, Acari): evidence from stable isotope ratios $\left({ }^{15} \mathrm{~N} /{ }^{14} \mathrm{~N}\right)$. Soil Biol. Biochem. 36, 1769-1774. doi: 10.1016/j.soilbio.2004.04.033

Sereda, E., Wolters, V., and Birkhofer, K. (2015). Addition of crop residues affects a detritus-based food chain depending on litter type and farming system. Basic Appl. Ecol. 16, 746-754. doi: 10.1016/j.baae.2015.07.005

Tiunov, A. V. (2007). Stable isotopes of carbon and nitrogen in soil ecological studies. Biol. Bull. 34, 395-407. doi: 10.1134/S106235900 7040127

Tsiafouli, M. A., Thébault, E., Sgardelis, S. P., Ruiter, P. C., Putten, W. H., Birkhofer, K., et al. (2015). Intensive agriculture reduces soil biodiversity across Europe. Global Change Biol. 21, 973-985. doi: 10.1111/gcb.12752

Voigtländer, K., and Düker, C. (2001). Distribution and species grouping of millipedes (Myriapoda, Diplopoda) in dry biotopes in Saxony-Anhalt/Eastern Germany. Eur. J. Soil Biol. 37, 325-328. doi: 10.1016/S1164-5563(01) 01104-9

Wardle, D. A., Bardgett, R. D., Klironomos, J. N., Setälä, H., van Der Putten, W. H., and Wall, D. H. (2004). Ecological linkages between aboveground and belowground biota. Science 304, 1629-1633. doi: 10.1126/science.1094875

Wolters, V., and Ekschmitt, K. (1997). "Gastropods, isopods, diplopods, and chilopods: neglected groups of the decomposer food web," in Fauna in Soil Ecosystems, ed G. Benckiser (New York, NY: Marcel Dekker Inc.), 265-306.

Zenger, J. T., and Gibb, T. J. (2001). Identification and impact of egg predators of Cyclocephala lurida and Popillia japonica (Coleoptera: Scarabaeidae) in turfgrass. Environ. Entomol. 30, 425-430. doi: 10.1603/0046-225X-30.2.425

Zhang, D., Hui, D., Luo, Y., and Zhou, G. (2008). Rates of litter decomposition in terrestrial ecosystems: global patterns and controlling factors. J. Plant Ecol. 1, 85-93. doi: 10.1093/jpe/rtn002

Conflict of Interest Statement: The authors declare that the research was conducted in the absence of any commercial or financial relationships that could be construed as a potential conflict of interest.

Copyright (c) 2016 Birkhofer, Dietrich, John, Schorpp, Zaitsev and Wolters. This is an open-access article distributed under the terms of the Creative Commons Attribution License (CC BY). The use, distribution or reproduction in other forums is permitted, provided the original author(s) or licensor are credited and that the original publication in this journal is cited, in accordance with accepted academic practice. No use, distribution or reproduction is permitted which does not comply with these terms. 